\title{
STUDY OF DIFFERENT APPROACHES TO PHOTOREALISTIC MODELLING AND RENDERING OF COMPLEX SURFACES
}

\author{
T. Dellarovere, M. Koehl, J. Rodrigues
}

Université de Strasbourg, CNRS, INSA Strasbourg, ICube Laboratory UMR 7357, Photogrammetry and Geomatics Group, 67000, Strasbourg, France - toma.dellarovere, mathieu.koehl, Johanna.rodrigues @insa-strasbourg.fr

\section{Commission II}

KEY WORDS: Heritage, Castle, 3D modelling, Historical constraints, Extraction, Realistic rendering

\begin{abstract}
:
Schwarzenburg Castle is one of the few Alsatian castles that can be dated with precision. The Schwarzenbourg family, taking advantage of a favourable historical and political context, built the castle in 1261 on the municipal boundary of the town of Munster. Initially intended for residential use, the castle passed through the centuries from family to family, and shortly becoming a ruin. The first major renovation was realized in the $15^{\text {th }}$ century, but for military purposes rather than for housing. This was the only one, as the castle was quickly abandoned at the end of the same century. It was only during the First World War that the castle was used by the German army, which built a bunker in the upper courtyard. Schwarzenbourg castle is, therefore, an original in Alsace, both in terms of its history and its characteristics, which have no regional equal. The objective of this modelling project is twofold. On the one hand, to model the current state of the castle, i.e., an advanced state of ruin for certain elements, and, on the other hand, to model the reconstruction of the castle as it was when it was built in 1261. This double objective comes up against several problems, mainly technical. Indeed, how to move from a point cloud of a certain density and quality to a surface model allowing a realistic rendering? How to limit the influence of the noise on the quality of the surface model? How to remain faithful to the cloud while simplifying the geometric primitives to make the rendering more efficient? Or what technique should be used to reconstitute the castle as it was when it was built? The objective here was to realize the transformation from a consolidated and geo-referenced point cloud to a surface model allowing for a photo-realistic rendering.
\end{abstract}

\section{INTRODUCTION}

\subsection{Historical context}

Schwarzenburg Castle, or also called Schwarzenberg Castle, is one of the few castles that can be accurately dated (Biller and Metz, 1995). Indeed, the construction of this castle, located in Munster, France, began in the spring of 1261 and ended a year later, which is a certain feat for the time and characteristics of the castle. The first owner and builder was Walter von Geroldseck of the Schwarzenburg family, then at the top of the local political spectrum. The Middle Ages being a time when periods of stability were rare, Schwarzenburg castle did not escape the situation and found itself tossed between several families. Indeed, in 1271 Walter von Geroldseck renounced the castle in exchange for a payment and, at same time, the abbey of Munster became part of the Bishopric of Basel. It was then that the castle became the possession of the Münch von Landskron family between 1341 and 1396 (Metz, 1983). The castle was mortgaged many times and slowly began to fall into ruin. It was not until 1401 that the Beger de Geispolsheim family recovered the property in exchange for a restoration (Biller and Metz, 1995). The castle was then modernized by Jacob Beger at the end of the XVth century. However, it fell into ruin again at the beginning of the Modern Era and lost all its interest and military value, as it was declared uninhabitable in 1646 (Biller and Metz, 1995). It can therefore be estimated that the castle must have been in an advanced state of ruin at this time. In 1800, the castle was sold as national property to a private owner in Munster and the German army built a bunker there during the First World War, which is still visible today. The castle now belongs to the city of Munster.

\subsection{Current status}

All preserved parts of the castle were built exclusively with clear granite found on the hill. These stones remained raw and were not cut, which complicated the distinction of the different phases of construction. In addition, the poor quality of the mortar used was partly responsible for the various collapses over the centuries (Biller and Metz, 1995). This information is crucial for texturing the ruins as well as reconstruction. Figure 1 reflects the state of the castle in 1995, it turns out that the state of the ruins remained almost identical to that of 26 years ago. Indeed, by making a comparison with the point clouds acquired at TLS over the last three years, very few differences were found. All the hatched elements of the high court are still visible today.
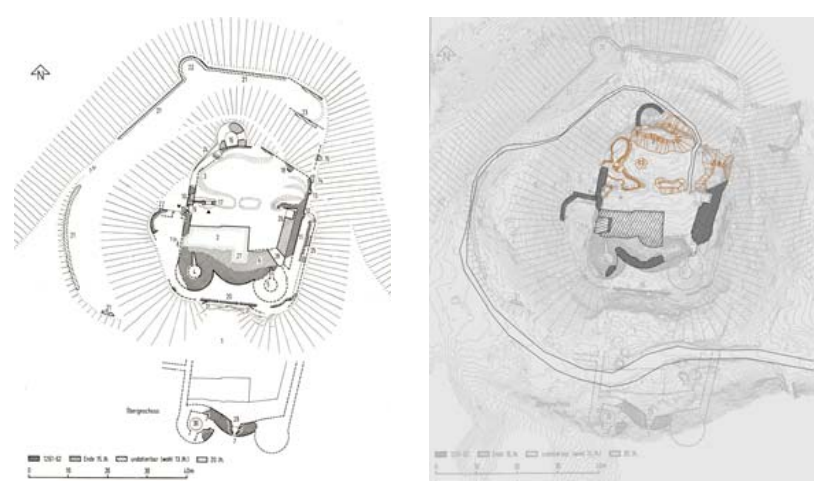

Figure 1: Technical drawing representing the different phases of the castle as well as the remarkable elements available for the reconstruction (Biller and Metz, 1995) and superposition of the DTM and point clouds. 
The farmyard sits on a narrow terrace below the high courtyard. Today, there is almost nothing left of it. It was estimated that the farmyard was built in a second time, and it may be in the XIII century.

\section{3D MODELLING OF COMPLEX SURFACE}

Heritage modelling, and particularly modelling of ruined heritage from point clouds, required different modelling approaches and methods compared to modelling heritage in better or even newer condition. Here we had to deal with complex surfaces for our castle, which were more difficult to model than simple surfaces.

\subsection{The problem of complex surfaces}

There exist several possible definitions of a complex surface. From a mathematical point of view, a complex surface can be considered as a complex two-dimensional whole. From a more pragmatic point of view, a complex surface is a surface that is difficult to parameterize using the equations of simple geometric primitives. Complex surfaces are usually surfaces with too much detail or variations in relief. It was then necessary to make a choice between a precise and detailed modelling of the initial object or the simplification of its representation by sampling the initial point cloud.

The associated problems were then of two kinds: first, the pure modelling and second, the appearance of the model. The problems related to modelling concern the editing and cleaning steps of the point cloud as well as the mesh from the original data (Remondino, 2011).

Care must then be taken to:

- choose the right software and algorithms for efficient processing of dense and sometimes heavy point clouds,

- find the best approach according to the level of complexity of the object to be modelled,

- use robust 3D mesh algorithms,

- choose export formats that limit the loss of information.

\subsection{Interest of 3D modelling}

This modelling is necessary for the conservation of heritage, and particularly of ruined heritage that is doomed to disappear over time. The objective was to be able to keep a trace, but also to be able to study the heritage, whether to make in-depth studies or to renovate it. Heritage modelling can be used in some cases to revive heritage that has been forgotten or of which there remains no trace today. This was particularly what has been done locally in Alsace with the modelling of the disappeared castle of Württemberg in Horbourg-Wihr (Cartier, 2020) (Koehl et al., 2020). In any case, although complex surfaces were a hindrance to $3 \mathrm{D}$ heritage modelling, it was not impossible and was even necessary from a cultural point of view.

\subsection{Surfaces used in modelling}

Mesh or polygonal surfaces: Mesh surfaces, also called polygonal or mesh, are the most easily achievable surfaces that make it possible to create objects consisting of vertices, edges and faces, all organized in polygons. Meshing consists of connecting, using edges, the different nodes of a point cloud to create faces. Each face consists of 3 nodes and 3 edges. There occur also methods of refining the mesh, via the creation of new points by interpolation between the created mesh and the starting point cloud (mesh in 2 steps).
NURBS surfaces: NURBS or Non-Uniform Rational Basis Splines are a precise mathematical representation of curves and surfaces whose shape is defined by control points (Barazzetti et al., 2015). The use of these points allowed a simplified modification of the shape and allowed a great interoperability between the different 3D modelling software. NURBS surfaces are the final step for object representation. They are based on NURBS curves. These surfaces can be estimated from one, two or more curves that act as a geometric constraint when interpolating surfaces. It is also possible to create surfaces by direct interpolation of the point cloud, but this method turns out to be less accurate than passing through curves. Indeed, by using the direct passage, the edges of the surface will not be well defined and will be of poor quality (Barazzetti et al., 2015). SUBD surfaces: Subdivision surfaces, known as SUBD surfaces, are a hybrid way of creating smooth surfaces based on the structure of NURBS curves and the detail of a mesh. This type of surface makes it possible to obtain a smoother rendering with a limited number of points. SUBDs tend to replace NURBS surfaces in modeling software, as they allow for faster and more accurate modelling. Subdivision surfaces are created using a recursive algorithm applied to a starting mesh. This algorithm works by subdividing the mesh, by creating new points and faces from the position of the old points. The resulting mesh will then have many more faces than the old mesh. It will then be possible to continue the recursive algorithm to obtain an even finer mesh. There are two types of subdivision schemes: interpolating schemes and approximating schemes (Habib and Warren, 1999).

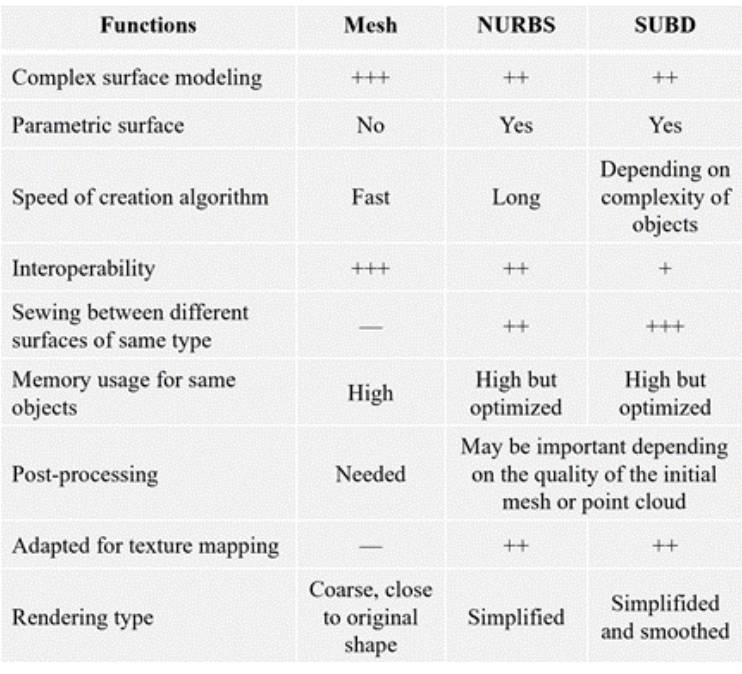

Table 1. Comparison of the different types of surfaces.

\subsection{Surface modelling approaches}

Unlike simple surfaces, complex surfaces are unique and therefore difficult to create by following conventional processes. Indeed, it is difficult, if not impossible, to look for the most likely equation of plans representing the ruins of a castle. There are several approaches to adapt to different situations:

- A classic 3D mesh approach, which makes it easy to obtain a 3D representation of an object,

- An approach resulting from the creation of HBIM and using the Scan-to-BIM method via NURBS,

- An approach derived from the use of DSM creation algorithms. 
The 3D mesh approach is the simplest approach from a computational point of view, because it is based on the creation of a set of triangles all around the object to be modeled.

The HBIM approach has been used in several studies (Diara and Rinaudo, 2020), (Barazzetti et al., 2015, 2016). The creation of surfaces following an HBIM approach allows the modelling of surfaces via a NURBS creation process. Although this approach is mostly applied to point clouds representing simple geometric primitives, it turns out that it is also possible to apply them to more complex surfaces, subject to sufficient computing power. The DSM-derived approach is an interesting approach for modeling objects whose point cloud is not dense enough or which has too much variation in relief. This approach is to be used when 3D meshes and HBIM approaches do not give conclusive results. The only negative point of this approach is the topology of the resulting mesh. Indeed, the algorithms for creating DSM will try to plate the edges of the mesh on a plane. It will then be necessary to leave more margin, during segmentation, to be able to subsequently rework the edge or sew it with other meshes. It is also necessary to perform a coordinate system transformation, the DSM using normals according to the $\mathrm{z}$ axis.

\subsection{Reconstitution approach}

The objectives of the reconstitution were identical to those of the modelling of complex surfaces, except for one detail, because here we seek to model a building as it was when it was built and not as it is today. In any case, the goal was to create a 3D model of the building that will then make it possible to make a realistic rendering thanks to the application of physical texture. This reconstruction was based exclusively on historical and architectural knowledge at a given moment. It was therefore important to have solid archives or hypotheses allowing modelling. In addition, as knowledge evolves over time, it was important to create a model that can be easily reused or exchanged between different software.

If complete archives are available, it's important to synthesize all the architectural and historical constraints. The objective of this synthesis is to be able to facilitate the analysis and interpretation of the data. This step is essential for the reconstruction of the various elements of a building (Cartier, 2020). If there is little or no archive available on the building to be reconstituted, the process is more complex. It is obviously impossible to envisage modelling without a minimum of information. In this case, it is necessary to go through the implementation of reconstruction hypotheses based on possible archaeological excavations, or on the architecture of comparable buildings. The support of archaeologists and historians is then essential.

To follow up on the analysis of the data, it was necessary to create the database that will then be used to model the building 3D. This base was a plan which represents the footprint, certain or extrapolated, of foundations, walls, etc. It was important that this plan was in digital format so that it can be used as a basis in 3D modelling software. In some cases, the archives already offer a hypothetical plan in paper format. In this case, if the latter includes a scale, it is easily possible to scan it. The modelling step was divided into two phases. The first was to roughly model the building by extrusion of the basic plan. This extrusion made it possible to give volume to our plan and consequently to create an overall shape of the building. The second step was to refine the $3 \mathrm{D}$ model by improving the quality of the details. This refining was done locally according to the constraints highlighted.
Realistic rendering: the main interests of $3 \mathrm{D}$ modelling are to be able to preserve the heritage, but also to represent it for study or tourist purposes. This representation goes through a photorealistic rendering, which proves to be easier to access with the software on the market. To achieve a rendering, it was important to use surfaces that allow the application of texture. These textures should be created from field information or archives. Textures were not the only components that make it possible to render successfully. Indeed, it was important to set up the scene to model, the position of the object, the environment, the position, and angle of the camera as well as the type and position of the lights. All these parameters cannot be neglected, and it was highly recommended to carry out this implementation from the beginning of the modelling.

\section{3D MODELLING OF THE RUINS OF SCHWARZENBURG CASTLE}

\subsection{Point cloud preparing}

The point cloud of the project (Figure 2), containing the scans of all the ruins of the castle as well as its close environment, was a point cloud that was considered raw, because it has not been cleaned, segmented, or sampled, etc. It was therefore necessary, at first and before moving on to $3 \mathrm{D}$ modelling, to prepare this point cloud by performing the previous actions.

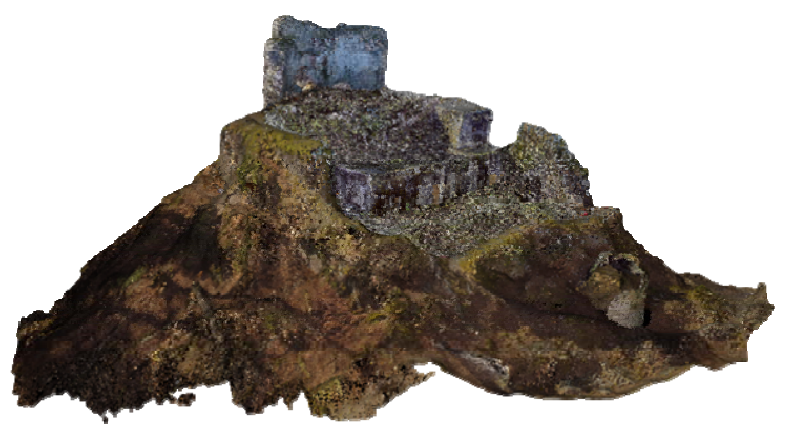

Figure 2: Overview of the point cloud of the castle and its environment.

\subsection{Data characteristics}

The data acquisition was carried out in several measurement campaigns. Conventional processing results in a fully consolidated and georeferenced cloud in RGF93-CC48 (EPSG:3948). A study on the quality of the dataset was carried out for its validation. The cleaning step, which includes the cleaning itself, as well as the de-noise of the cloud, was an important and necessary step for the smooth running of the 3D modelling. Indeed, the Schwarzenburg Castle was a castle that has been in ruins for several centuries. Vegetation has therefore taken over for many years, although the site has been maintained since the beginning of the twentieth century.

It was therefore necessary to eliminate from the cloud, the trunks of trees cut or not, the vegetation present on the top of the ruins, the elements too complex to model and off-site or the coarse noise. Once the coarse cleaning step has been completed, it was necessary to carry out a more meticulous cleaning through filtering (3DReshaper). Although this tool is a "black box" tool, we have chosen to use it because the extent of our data was small. It was therefore possible to easily visualize the result proposed by the tool before validating it. Finally, as cloud 
cleaning was a time-consuming and meticulous operation, it was advisable to carry out a first segmentation to separate the ruins from the ground.

The Figure 3 shows the whole project with a separation between DTM of environment and dense point cloud of near environment and ruins of castle. In the courtyard a bunker built by German army was also finely recorded.

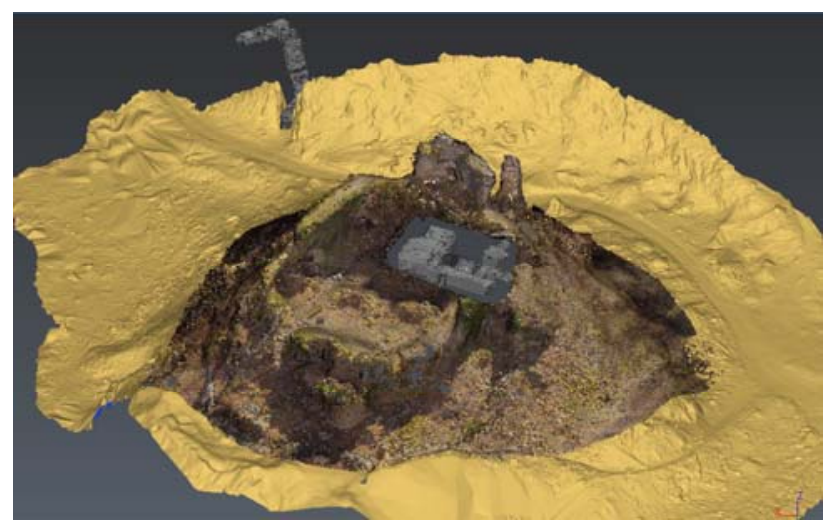

Figure 3: Ruins of castle and environment (DTM).

\subsection{First approach: 3D mesh in 2 steps}

The 3D mesh tool (3Dreshaper) can be used in one or two steps. The first version consists of making a regular mesh all around the object. Creation parameters such as the average length of the sides of the triangles, holes detection, creation of closed or open mesh, etc. must be set out. This is a "gray box" tool because only certain parameters can be modified. The second version of the tool, which is the one used throughout this study, is a two-step mesh generation, i.e., a coarse regular mesh and then a refinement of the mesh by interpolation. For keeping the detail of a point cloud in the resulting mesh, go through the first version of the tool. However, for simplifying the surfaces, the second version was totally suitable. Therefore, we used the second one, to obtain simpler and smoother surfaces and so to be able to achieve a possible realistic rendering later. Refining was carried out by resampling the vertices, which reintroduces noise due to the use of interpolation. As with the starting point cloud, the different meshes obtained were not perfect because of the complex surfaces they represent. It was therefore necessary to clean the obtained surface, which involves eliminating artifacts (purely visual), managing holes (calculating edge adjustment using interpolation based on a buffer distance from the initial edge), smoothing (using a neighborhood topology) and reducing the number of triangles.

The 3D mesh approach is an approach that can be considered easy to access. Indeed, no matter what complex surface to be modelled, we will always be able to have a result by playing with the modeling parameters.

Despite the advantages of this approach, it can be quickly realized that in cases where the cloud was not dense enough, complete, or even representing too much detail or variation in relief, the resulting mesh was not of good quality and requires post-production work that can be time-consuming. In addition, despite all the cleanings and improvements that can be envisaged, it happened that the mesh still had errors such as holes, double layers, non-manifold edges. In this case, there existed several solutions:

- Simplify the surface as much as possible, but in return, loose a lot of detail.

- Segment subsets into smaller subsets representing only the different faces of the same object. This approach improved 3D meshes, but in return it was necessary to deal with topology and face join problems to export the mesh in one piece.

- Use the approach derived from DSM.

\subsection{Second approach: DSM}

Complex surfaces that cannot be well modelled with the previous approach can be considered as complex relief with either little or too much detail. Using this hypothesis, it was possible to reason by analogy using the algorithms for creating DSM on our complex surfaces. The first step needed the rotation of the point cloud so that its faces were perpendicular to the $\mathrm{z}$ axis. Indeed, if this transformation was not performed, the DSM creation algorithm would use the upper faces, if there were any, or would not create any mesh if all the faces were almost on the same plane. It was important to note the coordinates of the origin point of the rotation as well as the axis of reference to return to the initial georeferencing after processing. Although this DSM approach made it possible to obtain closed and error-free meshes, there were still other problems to be solved. First, the edges of the mesh that were plated on the datum plane. It was then necessary to provide a wider edge during segmentation to be able to rework this edge afterwards before sewing the different meshes between them. Then, the holes that did not need to be filled were filled using this algorithm, it was necessary to recreate these holes manually by editing the mesh. To help with the reconstruction, it was possible to display the point cloud and the mesh at the same time which made it possible to better delimit the working area. It was also necessary to rework the edge as for the $3 \mathrm{D}$ mesh.

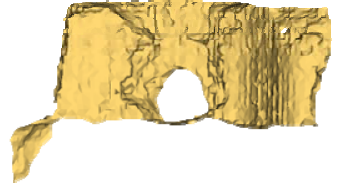

$5 \mathrm{~cm}$ density (first step)

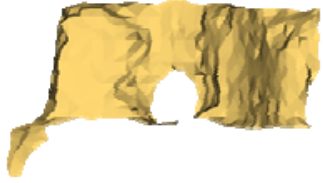

$10 \mathrm{~cm}$ density (first step)

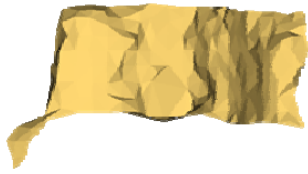

$15 \mathrm{~cm}$ density (first step)

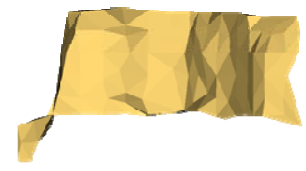

$20 \mathrm{~cm}$ density (first step)

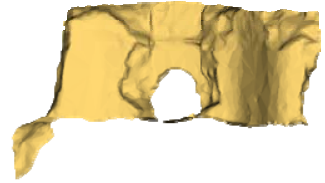

$5 \mathrm{~cm}$ density (second step)

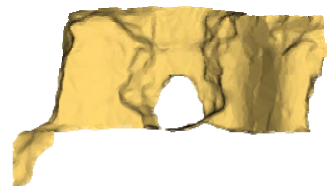

$10 \mathrm{~cm}$ density (second step)

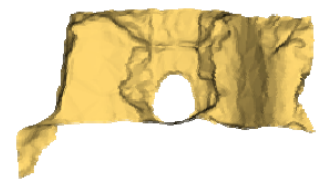

$15 \mathrm{~cm}$ density (second step)

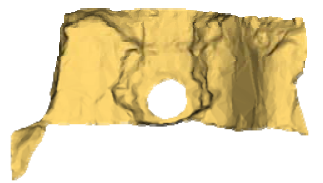

$20 \mathrm{~cm}$ density (second step)
Figure 4a: 2 steps mesh algorithm (3Dreshaper) 


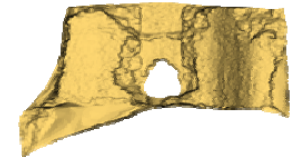

$2 \mathrm{~cm} \mathrm{DSM}$

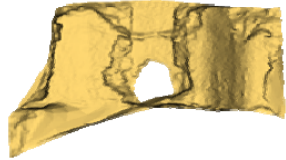

$5 \mathrm{~cm} \mathrm{DSM}$

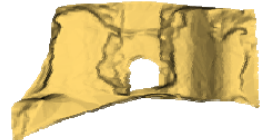

$10 \mathrm{~cm}$ DSM

Figure 4b: DSM algorithm

This approach derived from DSM allowed to overcome some of the problems encountered by 3D meshing. However, no approach was perfect, and each was accompanied by its own problems. Here for the DSM, despite an error-free mesh, the rework of the edges and holes of the model was required. The solution would then be to use a hybrid approach using 3D mesh for complex surfaces that accepts this method and the DSM approach for others. In any case, there was no single and perfect approach to correctly model any type of complex surface, because a generalist model cannot emerge. Figures 4 show the different results obtained after application of the different algorithms.

\subsection{Results}

All the results of the following comparisons derived from the CloudCompare software and more particularly from the $\mathrm{C} 2 \mathrm{M}$ (Cloud-to-Mesh Distance) algorithm. This algorithm can be used both to calculate the offset between a point cloud and a mesh, but also to calculate the distance between two meshes. It was preferred to use this open-source software to more easily access the operation of the algorithms used. This $\mathrm{C} 2 \mathrm{M}$ tool calculated the true distance between two entities, one of which will be the reference and the other will be the version compared. When the two entities were meshes, one could choose the role of each. However, when comparing a cloud and a mesh, the second one will be considered as a reference. To calculate the true distance, the algorithm used the vertices of the comparative entity and calculate the distance from the faces of the reference entity. If the orthogonal projection of the point was inside the face, the orthogonal distance will be calculated, otherwise if the projection falls outside, the distance from the nearest edge will be taken.

\begin{tabular}{|c|c|c|c|c|c|c|c|c|}
\hline $\begin{array}{c}\text { Type of } \\
\text { approach }\end{array}$ & $\begin{array}{l}\text { Sampling } \\
(\mathrm{cm})\end{array}$ & $\begin{array}{c}\begin{array}{c}\text { Average } \\
\text { difference } \\
(\mathrm{cm})\end{array} \\
\end{array}$ & $\begin{array}{c}\text { Standard } \\
\text { deviation } \\
(\mathrm{cm})\end{array}$ & $\begin{array}{l}\text { RMS of } \\
\text { scalar } \\
\text { field } \\
(\mathrm{cm})\end{array}$ & $\begin{array}{l}\text { Number } \\
\text { of points }\end{array}$ & $\begin{array}{c}\begin{array}{c}\text { File size } \\
\text { (ko) }\end{array} \\
\text { (1) }\end{array}$ & 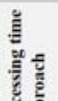 & ב \\
\hline \multirow{4}{*}{$\begin{array}{l}\text { 3D mesh } \\
\text { (first step) }\end{array}$} & 5 & 1,3 & 3.7 & 39 & 78680 & 193 & \multirow{4}{*}{ 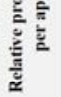 } & 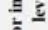 \\
\hline & 10 & 1,2 & 5,8 & 5,9 & 16504 & 37 & & \\
\hline & 15 & 39 & 7,4 & 7,4 & 6846 & 19 & & 玄 \\
\hline & 20 & 2,6 & 9,4 & 9,4 & 3621 & 9 & & \\
\hline \multirow{4}{*}{$\begin{array}{l}\text { 3D mesh } \\
\text { (second step) }\end{array}$} & 5 & 2 & 4 & 4,4 & nc & 291 & 4 & $*$ \\
\hline & 10 & 1,6 & 4,1 & 4,4 & $\mathrm{ne}$ & 245 & 3 & $* *$ \\
\hline & 15 & 1,5 & 4 & 4,3 & ne & 273 & 2 & $*$ \\
\hline & 20 & 1,5 & 4,3 & 4,5 & nc & 273 & $i$ & $* * *$ \\
\hline \multirow{3}{*}{ DSM } & 2 & $-5,1$ & 4,1 & 6.5 & $\mathrm{ne}$ & 8147 & 8 & . \\
\hline & 5 & $-4,5$ & 4,6 & 6,5 & $\mathrm{nc}$ & 1741 & 2 & $*$ \\
\hline & 10 & -4 & 5,3 & 6.6 & ne & 342 & $i$ & $*$ \\
\hline
\end{tabular}

The relative processing time per approach is considered on a scale of 1 to 10 where 1 is fast and 10 is very long. The operator's level of intervention is considered on a scale of $*$ to $* * *$ where $*$ represents little manipulation and $* * *$ a lot of manipulations.

Table 2: Absolute comparison of meshes versus unsampled source point cloud
An absolute comparison between meshes and a reference point cloud can be like an analysis of true deviations. Here, the standard deviation denomination was used and therefore performed a residue analysis, because despite all the care taken to clean the point cloud, it still contained noise, especially since part of the ruins has been overgrown with vegetation.

The analysis of this result table (Table 2) permitted to draw the following conclusions:

- The 3D mesh approach provided more accurate results than the DSM method. This conclusion resulted from the fact that the DSM mesh was carried out in relation to a plane. There was therefore interpolation of the data, while the 3D mesh approach remained more faithful to the starting point cloud.

- The 3D mesh method had less systematism than DSM modeling compared to the starting point cloud. Indeed, we noticed in the first case that the values of standard deviations and RMS were very close. Slight deviations may be due to low systematism and therefore a slight correlation. On the other hand, the two values for the DSM approach were more distant, which reflected the presence of a systematism and therefore a correlation.

- For the same object, sampling slightly modified the file size in the case of a $3 \mathrm{D}$ mesh. This was directly related to the number of faces in the mesh. However, for the DSM approach, the file size was multiplied by five each time the spatial resolution was halved.

- The relative processing time increased linearly in relation to the chosen sampling value. However, in the case of the DSM approach, it was multiplied by four each time the resolution was halved.

- Finally, the DSM approach required less operator intervention than the 3D mesh approach. Indeed, DSM meshes were cleaner than 3D meshes, because they were meshed relative to a reference plane (the rotated virtual ground). 3D meshes usually had more artifacts and especially when the density increased because of noise and strong variations in relief. This comparison allowed us to confirm previous conclusions that indicated that the best approach was a hybrid mesh using the 3D mesh approach and derived from DSM. Indeed, the 3D mesh, with good sampling, supplemented by the DSM approach made it possible to have a compromise in terms of detail, weight, processing time and level of operator intervention. In addition, in cases where the first approach gave unsatisfactory results or if we wanted to have much more detail locally, we could use the DSM approach.

In conclusion, this comparison showed that it was not relevant to compare meshes from two different approaches, because the construction methods, one in 3D space while the other in relation to the plan, made that there will necessarily deviations. This comparison also showed sampling limitations. Indeed, in the 3D approach, keep the starting resolution or the modifying slightly was the same statistically as doing a slightly larger sampling. For example, the mean values and standard deviations of the sampled meshes at 10 and $15 \mathrm{~cm}$ were almost identical. It would therefore be necessary to proceed in this way to limit the weight of the mesh while maintaining a good level of detail. This reasoning also applied to the DSM approach, where was no need to keep the initial sampling, as the weight and level of detail would be too great. In addition, to achieve a realistic rendering, it was necessary to obtain as few triangles as possible so as not to not overpower rendering engines. 
After making a comparison of the point clouds with each other under the same conditions, following the same approach and the same mesh parameters, it was interesting to compare the 3D mesh and SUBD approach. As a basis for this comparison a part of the southern towers divided into two pieces and then brought together by sewing process was used. The objective, in addition to comparing the approaches with each other, was to define the relevance of such a division of faces in the modelling process, but also to see if the sewing process was relevant.

The results of both modelling approaches were quite close, and even equivalent. Of course, these results depended on the algorithm of calculation of deviations used, but CloudCompare was considered reliable. SUBD mesh being obtained by individual mesh of two faces and then by sewing, it could be concluded that such a process was relevant because deviations from the overall 3D mesh were acceptable. Moreover, by this approach, it was possible to model a complex surface more easily. The file size of the SUBD mesh was much larger than that of the 3D mesh, which was due to the subdivision of the surfaces in the case of the SUBD to smooth it. With a view to realistic rendering, the SUBD mesh was preferable, which will facilitate the application of texture. On the other hand, it will be necessary to find a medium value in the intensity of subdivision to limit the number of faces to improve the rendering performance.

\section{MODELLING PROFILE}

During the different modeling tests on the ruins of the castle, we were able to obtain for the same face different levels of detail depending on the process and the approach chosen. To synthesize the different processes, but also to give the level of detail that we obtained in output, we propose a modelling profile, which is like a multi-choice protocol, but also to create a new definition of the level of detail called Level of Modelling. Based on the levels of detail (LoD) that have become widespread in BIM protocols, but also in GIS, the idea was of creating modelling levels (LoM) to generalize the types of models that were found at the output of the different processes. After an initial analysis, five different levels could be highlighted. They are detailed in Table 3 . These levels range from 1 to 5 where the larger the number, the higher the level of detail.

\begin{tabular}{|c|c|c|c|c|c|}
\cline { 2 - 6 } \multicolumn{1}{c|}{} & LoM 1 & LoM 2 & LoM 3 & LoM 4 & LoM 5 \\
\hline LoD & Poor & Correct & Good & High & Very high \\
\hline Error rate & $>50 \%$ & {$[25 ; 50]$} & $<25 \%$ & $<10 \%$ & $<10 \%$ \\
\hline Time cost & 1 & 2 & 3 & 4 & 5 \\
\hline $\begin{array}{c}\text { Operator } \\
\text { cost }\end{array}$ & 1 & 2 & $2-3$ & 4 & 5 \\
\hline $\begin{array}{c}\text { Weight } \\
\text { Light }\end{array}$ & $\begin{array}{c}\text { Light to } \\
\text { moderate }\end{array}$ & $\begin{array}{c}\text { Moderate } \\
\text { Important }\end{array}$ & Important & $\begin{array}{c}\text { Very } \\
\text { important }\end{array}$ \\
\hline $\begin{array}{c}\text { Ease of } \\
\text { conversion } \\
\text { NURBS } / \\
\text { SUBD }\end{array}$ & Easy and fast & $\begin{array}{c}\text { Easy but } \\
\text { longer }\end{array}$ & $\begin{array}{c}\text { Variable } \\
\text { and long }\end{array}$ & $\begin{array}{c}\text { Difficult } \\
\text { and long }\end{array}$ & $\begin{array}{c}\text { Very } \\
\text { difficult } \\
\text { and very } \\
\text { long }\end{array}$ \\
\hline $\begin{array}{c}\text { Use case } \\
\text { Visualization }\end{array}$ & $\begin{array}{c}\text { Visualization } \\
\text { overview, } \\
\text { realistic } \\
\text { rendering }\end{array}$ & $\begin{array}{c}\text { Analysis, } \\
\text { overview, } \\
\text { rendering, } \\
\text { realistic } \\
\text { rendering }\end{array}$ & $\begin{array}{c}\text { Analysis, } \\
\text { fine } \\
\text { modeling, } \\
\text { local } \\
\text { rendering }\end{array}$ & $\begin{array}{c}\text { Specific } \\
\text { needs, } \\
\text { detailed } \\
\text { analysis }\end{array}$ \\
\hline
\end{tabular}

Table 3: Level of Modelling (LoM)
Table 3 shows the different characteristics of the proposed modelling levels.

The modeling levels are characterized by the following specifications:

Level of detail: It represents the level of visual detail that can range from low (simplified reality) to very high (very close to reality).

Error rate: The specification trying to characterize the percentage of error that can be found if we compare the model with reality (point cloud).

Cost in time: Allows to characterize the time taken by the entire modeling process, including calculations. This cost is evaluated on a scale of 1 to 5 where 1 represents a fast process and 5 a very long process.

Operator cost: Allows to characterize the need for manipulation carried out by the operator. This cost is estimated on a scale of 1 to 5 where 1 represents a semi-automatic process, or even quasi-automatic, and 5 represents a quasimanual process with a lot of manipulation.

Weight: Represents the impact of the model on the computer's memory usage. The weight can range from light to very large. NURBS / SUBD conversion ease: Relative evaluation by experience of the ease of converting a mesh to NURBS or SUBD under Rhino3D software.

Usage: Shows the main uses for each level of modeling.

\section{RENDERING}

First, it was important to clarify the difference between a material and a texture, as sometimes there was confusion between the two terms. Texture refers to the envelope of an object, that is, its appearance. Most of the time, images were placed on the object, although there were also more general motifs such as checkerboards, dots, gradients, granite, marble, etc

Material refers to the physical properties of the object that allows it to be seen correctly according to its environment. Among these properties, it is usual to find diffusion, reflection, roughness, transparency, metallic effect, etc. For example, an object without physical properties will not be able to be transparent or reflect light in realistic renderings made using a rendering engine.

In the case of complex surfaces, the problems were not really related to the materials, and therefore to the physical properties, but more on the application of photo-realistic texture. Indeed, thanks to field operations and various studies, it was possible to know or approximate the materials that make up a building. Therefore, it was easy to change the parameters of realistic materials in software to those of the original natural materials. However, the application of texture from images taken in the field, which may even have been used to create the point cloud by photogrammetric calculations, was not possible because of the particular context. This impossibility was because it was difficult to perfectly recreate the object as it existed or as it was represented by the point cloud, because regardless of the mesh operation chosen, it will include a phase of simplification of the model and at least a reduction in the number of triangles. It will then be impossible to perfectly recreate a texture using the images taken in the field, because there will no longer be a correlation between the pixels of the images and the nodes of the resulting mesh (Kersten and Stallmann, 2012).

One solution to get around this problem would be to create and apply artificial materials and textures via the tools made available by the software. Indeed, in recent years, we have seen the development and generalization of realistic physical 
rendering techniques that include all $3 \mathrm{D}$ rendering techniques to imitate physical models describing the behavior of light in the real world. These techniques are based on the use of realistic material whose parameters can be modified. In addition, it is also possible to use an image as a reference for each parameter. In this case, the images are usually shaded in gray, so that the software can vary the intensity of the parameter according to the value of the pixel.

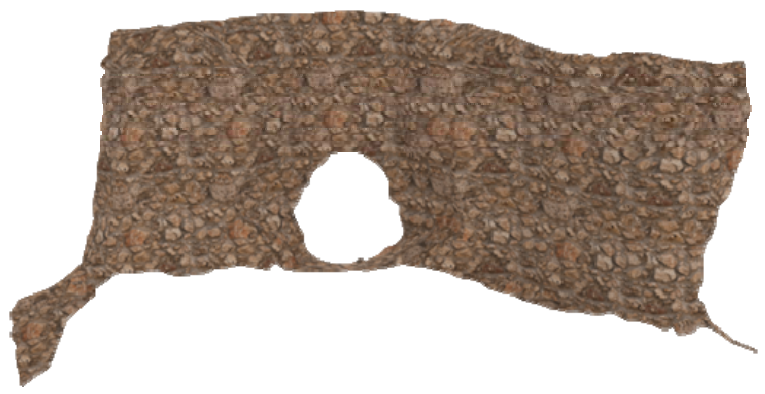

Figure 5: Rendering with realistic texture

Figure 5 shows a realistic rendering of one of the faces of our castle on which we applied a material and an artificial texture of medieval stone type.

Renderings were made in the various useful places for a more detailed analysis of the ruins or for measurement needs before restoration (Figure 6).
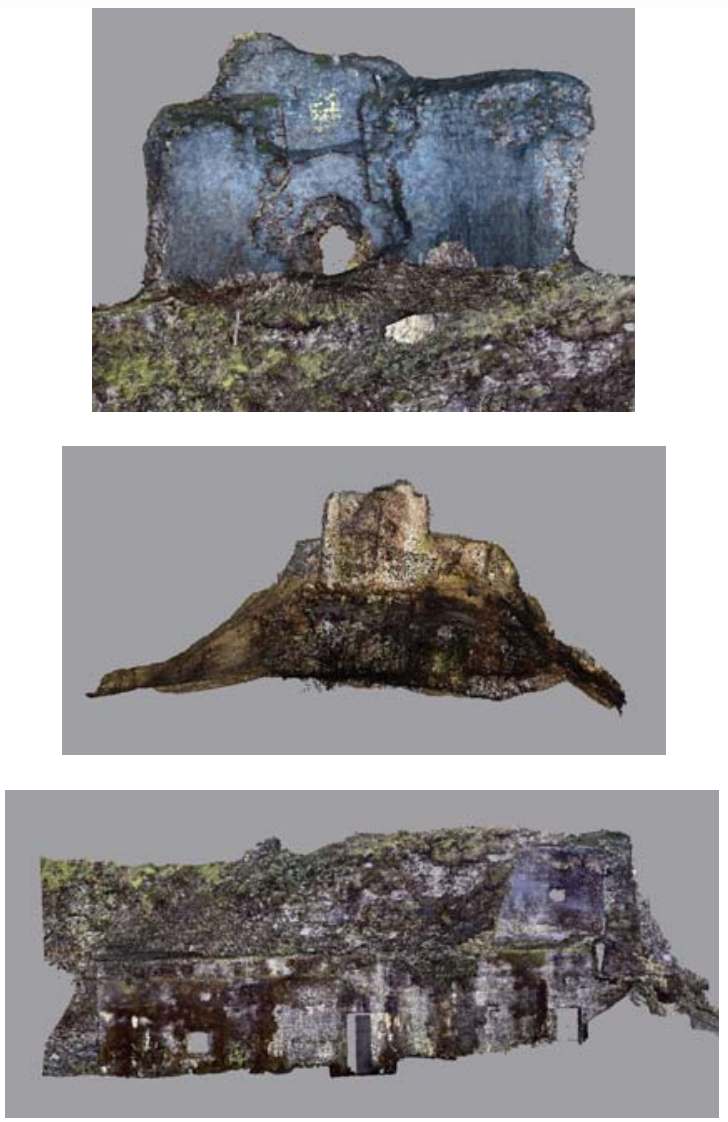

Figure 6: Different renderings of characteristic places.
Figure 7 shows first tries for restitution of the initial castle.

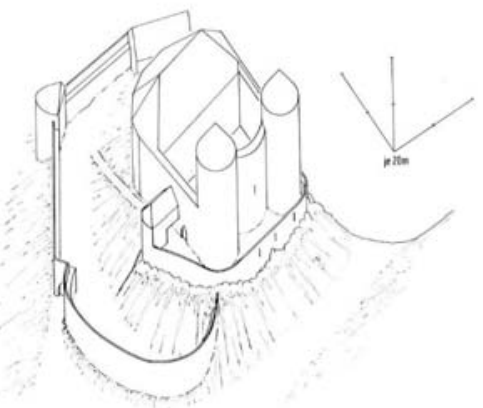

Figure 7a: Isometric reconstruction carried out by (Biller and Metz, 1995), which uses all the hypotheses collected.

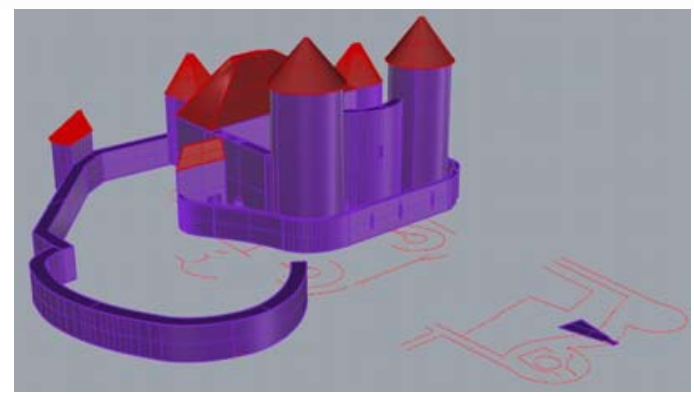

Figure 7b: Digital reconstruction.

\section{CONCLUSION AND PERSPECTIVES}

This project made it possible to conduct a study on complex surfaces and 3D modeling approaches. Subsequently, we were able to process the entire cloud, cleaning it, denoising it and then segmenting it, all to allow simplified modelling of the different elements. At present, most of these elements have been segmented either by 3D meshes or by DSM meshes. We were also able to perform an analysis of the influence of point cloud quality on the quality of the resulting mesh. Finally, all the research as well as the practice, allowed resuming the various modeling profiles, as well as to create a level of modeling called LoM. It is important, now, to finish the modelling started of the ruins, which consists in a final improvement of the meshes as well as seams. In addition, the reconstruction of the castle under Rhino3D was carried out in broad outline, so it remains to refine the model and specially to match it with its environment such as the ground.

The previous two approaches can be applied to the entire project. A segmented model of the ruins of the castle has been generated. However, it remains to realize a complete and reworked model, to take over the existing meshes, to manage the topology for a realistic rendering, but also to configure the scenes (environment, light, etc.). Currently, all the meshes have been made with the 3DReshaper software and can be easily exported in OBJ format. It is now necessary to choose a modelling and final rendering software (Rhino3D, Blender, Maya, etc.) to incorporate all the meshes and prepare the rendering. To achieve a realistic rendering, additional research should be carried out on the type of materials present on the site, but also on the possibility of creating custom textures from images taken in the field. Once the final 3D model is completed, it will be possible to easily create a virtual tour of the site, which can be reused for cultural purposes. 


\section{REFERENCES}

Barazzetti, L., Banfi, F., Brumana, R., Previtali, M., 2015. Creation of Parametric BIM Objects from Point Clouds Using Nurbs. The Photogrammetric Record, 30(152), pp. 339-362. https://doi.org/10.1111/phor.12122

Barazzetti, L., 2016. Parametric as-built model generation of complex shapes from point clouds. Advanced Engineering Informatics, 30(3), pp. 298-311.

https://doi.org/10.1016/j.aei.2016.03.005

Biller, Th., and Metz, B., 1995. Die Burgen des Elsaß. Bd.3 : Der frühe gotische Burgenbau im Elsaß (1250 - 1300). Deutscher Kunstverlag, München, 1995, 307 pages. ISBN 9783-422-06132-3.

Brumana, R., Oreni, D., Barazzetti, L., Cuca, B., Previtali, M., Banfi, F., 2020. Survey and Scan to BIM Model for the Knowledge of Built Heritage and the Management of Conservation Activities. In: Daniotti B., Gianinetto M., Della Torre S. (eds) Digital Transformation of the Design, Construction and Management Processes of the Built Environment. Research for Development. Springer, Cham, pp. 391-400. https://doi.org/10.1007/978-3-030-33570-0_35

Canciani, M., Falcolini, C., Saccone, M. \& Spadafora, G., 2013. The architectural 3D survey vs archaeological 3D survey. In: 2013 Digital Heritage International Congress (DigitalHeritage). October 2013, IEEE, Marseille, France, pp. 765-765. https://doi.org/10.1109/DigitalHeritage.2013.6743839

Cartier, L., 2020. Modélisation 3D du château disparu des Wurtemberg à Horbourg-Wihr et exploitation de la réalité augmentée pour une mise en valeur dans la trame urbaine contemporaine. Revue XYZ (162), 2020, pp. 63-68. ISBN 02909057.

Chen, S., Yang, H., Wang, S., \& Hu, Q. (2018). Surveying and Digital Restoration of Towering Architectural Heritage in Harsh Environments: a Case Study of the Millennium Ancient Watchtower in Tibet. Sustainability, 10(9), 3138.

https://doi.org/10.3390/su10093138

Diara, F., and Rinaudo, F., 2020. Building archaeology documentation and analysis through open source HBIM solutions via nurbs modelling. Int. Arch. Photogramm. Remote Sens. Spatial Inf. Sci., XLIII-B2-2020, pp. 1381-1388. https://doi.org/10.5194/isprs-archives-XLIII-B2-2020-13812020

Habib, A., and Warren, J., 1999. Edge and vertex insertion for a class of c1 subdivision surfaces. Computer Aided Geometric Design, 16(4), pp. 223-247. https://doi.org/10.1016/S01678396(98)00045-4

Hu, Q., Wang, S., Fu, C., Ai, M., Yu, D., \& Wang, W.,2016. Fine surveying and 3D modeling approach for wooden ancient architecture via multiple laser scanner integration. Remote Sensing, 8(4), 270. https://doi.org/10.3390/rs8040270

Kersten, T. P. and Stallmann, D. 2012. Automatic texture mapping of architectural and archaeological 3D models. Int. Arch. Photogramm. Remote Sens. Spatial Inf. Sci., XXXIX-B5, pp. 273-278. https://doi.org/10.5194/isprsarchives-XXXIX-B5273-2012
Koehl, M., Fuchs, M., Nivola, T., Koch, J., Cartier, L., and Soussoko, S. 2020. When roman antiquity and renaissance came together in virtual 3D environment: 3D modelling considerations, Int. Arch. Photogramm. Remote Sens. Spatial Inf. Sci., XLIII-B4-2020, pp. 607-614, https://doi.org/10.5194/isprs-archives-XLIII-B4-2020-607-2020

Masiero, A., Chiabrando, F., Lingua, A.M., Marino, B.G., Fissore, F., Guarnieri, A. \& Vettore, A.,2019. 3D modeling of GIRIFALCO fortress. Int. Arch. Photogramm. Remote Sens. Spatial Inf. Sci. Vol. XLII-2/W9, pp. 473-478. http://dx.doi.org/10.5194/isprs-archives-XLII-2-W9-473-2019

Mengus, N. \& Rudrauf, J.-M., 2013. Châteaux forts et fortifications médiévales d'Alsace : dictionnaire d'histoire et d'architecture. La Nuée bleue, Strasbourg.

Metz, B., 1983. Enquête: Le château de Schwarzenberg Histoire et architecture. Saisons d'Alsace, (80-81): pp. 27-60.

Murtiyoso, A.D., 2020. Relevé 3D et classification de nuages de points du patrimoine bâti. $P h D$ Thesis, 147 pages, Université de Strasbourg, Strasbourg.

https://tel.archives-ouvertes.fr/tel-02953668

Remondino, F., 2011. Heritage recording and 3D modeling with photogrammetry and 3D scanning. Remote sensing, 3(6): pp. 1104-1138, 2011. https://doi.org/10.3390/rs3061104 